complications and unusual apparatus. There was no need to change the technique so long as it could give decisive answers, and they were decisive because the right questions were asked. In fact, he has been ready to adopt whatever new method would be more effective ; but for Dale the technique has always seemed to follow the problem and rarely to suggest it.

\section{Assembling of Evidence}

This may do less than justice to the strategy which has led to so many advances. An attack cannot be planned without regard to the arms which can be employed, and Dale has always known where to find them and what to expect from them. His many collaborators and pupils have never found him set in his ways; it is rather that he can develop his theme with such knowledge and authority that in the completed account of an investigation we follow the argument and rarely stop to think of all the difficulties which must have been surmounted in assembling the evidence for it. Yet no one can have seen Dale at work in the laboratory or listened to his communications to the Physiological Society without realizing that it is the evidence which is all-important. Dale has never let his theories take charge: often enough his evidence has led to elaborate theorizing by others-about the role of histamine for instance, or about humoral transmitters in the nerve fibre. When such new horizons are opened it is hard to keep to the solid and familiar ground, but Dale has been more concerned to apply the brake than to be first in the gold rush. The gold he has found will keep its value.

Those who have listened to his lectures must often have been surprised to learn that he has never occupied a professorial chair at a university. He would have shone in teaching as he has in research, and medical education would have profited by his wisdom. But he has taught the whole body of physiologists throughout his career, through the medium of his published work and even more by his personal contact with them at congresses and symposia. For many years he has set the example at the International Congresses of Physiology by showing the rank and file how much more interesting a communication can be when it is clearly presented and illustrated. All of us are agreed that the kymographic records which bear the hall-mark of the National Institute for Medical Research have set a standard which few laboratories can hope to reach.

Such virtues are no doubt of minor account in comparison with Dale's specific achievements in the field of scientific investigation, but his effect on the development of medical science generally has been of major importance. Though he could not serve on the Medical Research Council when he was Director of the National Institute, his ideas have played a large part in the policy of the Council, and his direction of the Institute has led to many developments in fields remote from physiology and pharmacology.

To have remained as fertile in his own researches as Dale has done, as accessible and as encouraging to his juniors, and yet to have made his Institute famous for the variety as well as the standard of its performance is an index of talents and personal qualities which can only arouse our admiration. We cannot feel envy at the power to have accomplished so much; it is too far beyond our reach.

\section{SALUTE TO HENRY HALLETT DALE}

BY

OTTO LOEWI, M.D.

Foreign Member of the Royal Society

Sir Henry Dale's eightieth birthday is a welcome occasion for reflections on what science in general and scientists themselves owe to him. Such retrospection is especially gratifying to one who has had the good luck to enjoy Henry Dale's friendship for more than half a century. We met for the first time in 1903, in the small and poorly equipped, yet extremely creative and dynamic laboratory of Ernest Starling. Our interests and aspirations had much in common, and before long a close mutual relationship developed, from which emerged our lifelong friendship. This was deepened when, as time went on, our main interest and work coincided in the field of the chemical transmission of nervous impulses. That such a mechanism existed had been seriously considered first by Elliott (1904) and then by Dale (1914), because of the correspondence they had noted between the effects produced by adrenaline or acetylcholine and those due to the activities of sympathetic or parasympathetic nerves respectively. Later the chemical transmission of impulses from post-ganglionic nerves was established, and then Dale demonstrated, through ingenious planning, methods, and experiments, that the chemical transmission holds good to a much greater extent than I had realized. No better evidence of this can be offered than a quotation from a certain Harvey Lecture (1933): "I personally do not believe in a humoral mechanism in the case of striated muscle." Within the next year Dale demonstrated the chemical nature of transmission from spinal nerves to striated muscles. It was a discovery that made me happy, which may seem strange in view of the sentence just quoted. But it was not strange at all, for the fact stood forth that physiology owed and still owes to Dale the knowledge that the transmission of impulses from all peripheral, efferent nerves to their effector organs is of chemical nature.

It is fascinating to follow Dale's development from the very beginning. $\mathrm{He}$ was introduced to experimental medicine by some of the great physiologists of those days: Gaskell, Langley, Anderson, Starling, and Bayliss. At the age of 29 he accepted a post as independent research worker in the Wellcome Physiological Research Laboratories. He has since said: "I was attracted to the offer ... by an instinctive feeling that it would be a good thing for me, at that stage, to be obliged to stand scientifically on my own feet, to find my own problems, to plan my own experimental attack upon them, to learn and devise methods for myself and to make my own mistakes." Dale's continual development ever since has fully justified the early confidence he had in himself. His scientific achievements, here dealt with in tributes from Lord Adrian and Professor Burn, were of such distinction that soon he became a leader in the fields of pharmacology and physiology and attracted a great number of ardent young associates from many lands. Endowed with imagination, strengthened by self-criticism, and urged on by a contagious enthusiasm and intellectual curiosity, he probed into the very roots of his problems and in doing so became an inspiring educator. He familiarized his students not only with facts, methods, and the art of observing and experimenting, but with ways of scientific thinking and 
with the principles applicable to any field of experimental science. And more than all this, Dale became and has remained a scientific father and personal friend to his pupils. Small wonder that every single one of them cherishes a deep, unfaltering devotion to him.

In time the realm of Dale's interests expanded so widely that he became master of the essential problems in nearly every branch of experimestal medicine. It became almost a routine for cther men of wide scientific knowledge to turn to him for advice or to call upon him-again and again from across the Atlantic-to be the chief speaker at the dedication of research institutes. Hardly anyone else would have dealt with the possibilities of these institutes from so many angles or have so clearly indicated the direction research should take in the future. By such deeds Dale has shown himself to be a pre-eminent elder statesman in science.

For years Dale has been besought to deliver speeches on general themes and to commemorate famous men or anniversaries and to dignify special occasions. By consenting to the publication of a selection of such lectures and addresses in a book called An Autumn Gleaning, Dale has given us opportunity to broaden our knowledge of his thought and personality. He is as generous in appreciation of the achievements of others as he is modest about his own. In the introduction to the book just mentioned, he suggests that it may be " a late aftermath of weeds." I agree with the reviewer (Hugh Taylor, American Scientist, Vol. 43, p. 36, April, 1955) who calls the book " a golden harvest."

Dale's training at Trinity, one of the foremost humanistic colleges, may in part be responsible for his leaning to the historical aspects of science. He follows up the growth of ideas through the centuries and sees scientific developments in their proper setting. Over and beyond his education he possesses the capacity to grasp what is essential. His fiair for the essential in any matter is generally recognized. English friends have related to me more than once that, whenever a scientific discussion becomes entangled, everybody eagerly waits for Dale to rescue it; he always makes the point.

Another characteristic of Dale's is his unusual talent to express the wealth of his thoughts by means of deeply penetrating words. More than that he has an artistic mode of formulation, which should serve the younger generation as a prototype of simplicity, lucidity, and beauty.

I finally desire to emphasize-have tried indeed to do it all along - that Dale's intellectual and aesthetic culture are attended by a strong ethical sense. He has a deep feeling of moral obligation. It shines through everything he writes or speaks. He has a genuine eagerness for any good cause.

To do justice to Dale's personality as a whole would require a big volume. In a short essay like this, only a few of his innumerable facets can be singled out.

The achievements of creative men in science, art, and music originate almost entirely from their aspiration to make the best possible use of their natural endowments. Doing so, they are happy and they do not claim gratitude. Their fellow men are grateful to them, in part because they benefit by their achievements, but for a larger reason as well, because these achievements testify to the heights that can be reached by mankind. Contemplating their deeds, we feel pride, courage, and optimism. On Henry Dale's eightieth birthda'y I feel joy in saying this to him:

Happy birthday, dear old friend.

\section{SIR HENRY DALE'S CONTRIBUTION TO THERAPEUTICS}

BY

\author{
J. H. BURN, M.D., F.R.S. \\ Professor of Pharmacology, University of Oxford
}

In considering Sir Henry Dale's contributions to therapeutics it is right to mention first his discovery of the action of posterior lobe pituitary extract on the uterus. Though he published no paper dealing specifically with the action of this extract until 1909, there is a record of the stimulant action on the uterus of the cat in his paper on "The Action of Ergot," which appeared in the Journal of Physiology in 1906. He pointed out the significance of this effect, since he had shown that the uterus of the cat in the non-pregnant state, unlike that of many other animals, was caused to relax by sympathetic stimulation and by the action of sympathomimetic amines.

Dale's main interest until the end of the first world war was in problems which were at first sight academic ; his work on the action of histamine on the capillaries, however, had a great impact on clinical thought. It is hard to remember that up to 1918 the current view was that of Tigerstedt, according to which the capillaries lacked the power to contract and were purely passive structures. Dale and Richards in 1918 were the first to demonstrate that the vasodilator action of histamine seen in the body was due to capillary dilatation, and that a state of capillary constriction could be maintained under certain conditions in a perfused limb. This indicated that the capillaries behaved as though they had a tone of their own. Krogh's work, based on the direct observation of capillary changes and published only a few months later, confirmed and amplified the conception of independent capillary activity in great detail.

While the evidence of Dale and Richards and of Krogh was of interest mainly to physiologists, the work of Dale and Laidlaw on histamine shock brought the importance of capillary dilatation and of capillary permeability to the minds of physicians, surgeons, and pathologists alike. Dale and Laidlaw demonstrated that the injection of histamine into the cat anaesthetized with ether caused a profound and irreversible fall of blood pressure due to stagnation of blood in the widely dilated capillaries of the intestine, and that the blood in the main vessels became concentrated by loss of fluid through the capillary walls.

An interesting observation which is still not fully explained appeared in the first paper of the first volume of the British Journal of Experimental Pathology. Dale showed that when a cat was anaesthetized with ether or chloroform for some time, and then without operation allowed to recover, it remained for many hours highly sensitive to the effect of injected histamine. Collapse was caused by an amount of histamine onetenth of that which was without effect on the cat before it received the anaesthetic.

\section{Biological Standardization}

The most important contributions to therapeutics were no doubt, those which came under the heading of biological standardization. The importance of accurate dosage of drugs was always recognized by those who compiled the various pharmacopoeias, but its full gravity was appreciated only when the number of potent remedies underwent rapid 